defective down and in, and the tension was subnormal. The left eye was normal with a vision of $6 / 6$. The patient was kept in bed for three weeks, atropin being instilled in the right eye.

On July 23 , the vitreous had partially cleared and there was no commotio retinae. The retina was seen to be in position, but the disc was obscured by an unusual appearance, details of which, owing to the state of the vitreous, could not be made out till August 2, when a good view was obtained. The disc was then seen to be included in a horizontally oval ectatic area bounded internally by the disc margin and extending outwards towards the macula. The area presented a much paler reflex than the rest of the fundus and was sharply defined, except below, by superficial retinal pigmentation. - Round the macula there was dense pigmentation and between the disc and macula there was pigmentation and some cicatricial tissue formation. The retinal vessels, on entering the area, showed a decided bend similar to that seen in early glaucomatous cupping and, once in the ectasia, they were out of focus. The walls of the ectasia were steep at the disc, above and below, but towards the matula the slope was more gradual. The ectasia was rather too shallow for accurate measurement; the disc was the deepest part and vessels there were brought into focus by minus two dioptres. Below the area there was much retinal degeneration, and at the periphery the only abnormality was guttate pigmentation.

The patient could count fingers at six inches, projection was defective down and in, and the tension was subnormal.

\title{
INTRA-OCULAR HAEMORRHAGE AFTER GUTHRIE'S SECTION \\ BY
}

Alan W. Sichel, M.D.

RESIDENT SURGICAL OFFICER, BIRMINGHAM AND MIDLAND EYE HOSPITAL.

THE three cases recorded below are of interest as illustrating an unusual complication following the performance of Saemisch's, or, more correctly, Guthrle's section for corneal ulcer.

CASE I.-H. G., aet. 52, was admitted to the Birmingham and Midland Eye Hospital on November 14, 1919, suffering from a hypopyon ulcer of the left eye. There was no history of injury. The eye had been affected for eight weeks. Guthrie's section was performed under cocain on the evening of admission. At the first dressing on the following day the condition of the eye was satisfactory. About two hours later the patient complained of pain, and on the dressing being removed the lens in its capsule was found adhering to the pad. The dressing was reapplied. About one hour later further pain was complained of, and on removing the pad vitreous was seen to be protruding through the gaping corneal wound. The eye was eviscerated the same afternoon. On 
removal of the vitreous large masses of dark blood clot came away.

The records of this case further show: R.V. 6/6. Fundus normal. R. tension, on digital examination, normal. Blood pressure, maximum systolic at radial, $132 \mathrm{~mm}$. $\mathrm{Hg}$.

CASE II.-C. C., aet. 54, was admitted to the Birmingham and Midland Eye Hospital on January 4, 1920, with a hypopyon ulcer of the left eye following an injury by the twig of a hedge two weeks previously. Guthrie's section was performed under cocain on the following day. The eye was dressed twice daily on the first two days after operation and the condition found to be satisfactory. On the 7 th inst., viz., three days after operation, the wound was found to be bulging and the lens in its capsule came away on the dressing followed by vitreous. Evisceration was carried out the same day.

- Unfortunately no record was kept of blood pressure or tension, but the case sheet shows: R.V. 6/9, fundus normal.

CASE III.-W. M., aet. 44, was admitted to the Birmingham and Midland Eye Hospital on January 9, 1920, suffering from an extensive ulcer of the right cornea unaccompanied by hypopyon. The eye had been injured ten years previously, and on admission was divergent, with vision reduced to hand movements, and tension much raised. On January 13, progress not being satisfactory, Guthrie's section was performed under cocain. The condition of the eye remained satisfactory until the 15th inst., viz., two days after operation, when, about 5 p.m., the lens intact in its capsule was found on the dressing. The patient was seen at 8 p.m. and stated that he was quite comfortable. Five minutes later very intense pain was complained of, followed in half an hour by a severe expulsive haemorrhage. The eye was enucleated the same night. On section after removal, there was found complete detachment of the retina, the whole vitreous chamber being filled with blood ; the optic disc was markedly cupped.

The condition of the left eye was as follows: V. $6 / 6$; fundus normal ; tension, by Schiötz tonometer, $26 \mathrm{~mm}$. Hg. The maximum systolic blood pressure at the radial was $180 \mathrm{~mm}$. $\mathrm{Hg}$.

The operation in each case was performed in the usual manner, a Graefe knife transfixing the eye from clear cornea to clear cornea on either side of the ulcer and coming out through the base of the latter, The incision extended almost the entire width of the cornea in its horizontal diameter. The lenses were not injured at the time of operation, as witnessed by the fact that in each case they were found intact in their capsules after extrusion.

It is stated by Török and Grout ${ }^{1}$ that the lens and vitreous may escape at the time of operation when performed under cocain if the patient should squeeze, but the perusal of an extennsive literature reveals no record of such a complication occurring as late as two to three days after operation. 
In Case III the sudden lowering of a raised tension may account for the occurrence of intra-ocular haemorrhage, but this cannot apply to Cases I and II unless there were antecedent vascular degenerative changes in the retinal or choroidal vessels of which there is no evidence.

It has been thought worth while to record the occurrence of this unusual complication in view of the fact that Guthrie's section is an operation resorted to not infrequently in cases of hypopyon keratitis.

My thanks are due to Mr. Jameson Evans, Mr. Fulford Eales, and Mr. Harrison Butler for permission to publish the notes of these cases.

\section{REFERENCE}

(I) Török and Grout.-Surgery of the Eye, p 136,

\section{A TONOMETRIC CHART \\ BY}

T. HARRISON BUTLER, LEAMINGTON SPA.

CONSIDERABLE time may be wasted in hospital work when a case

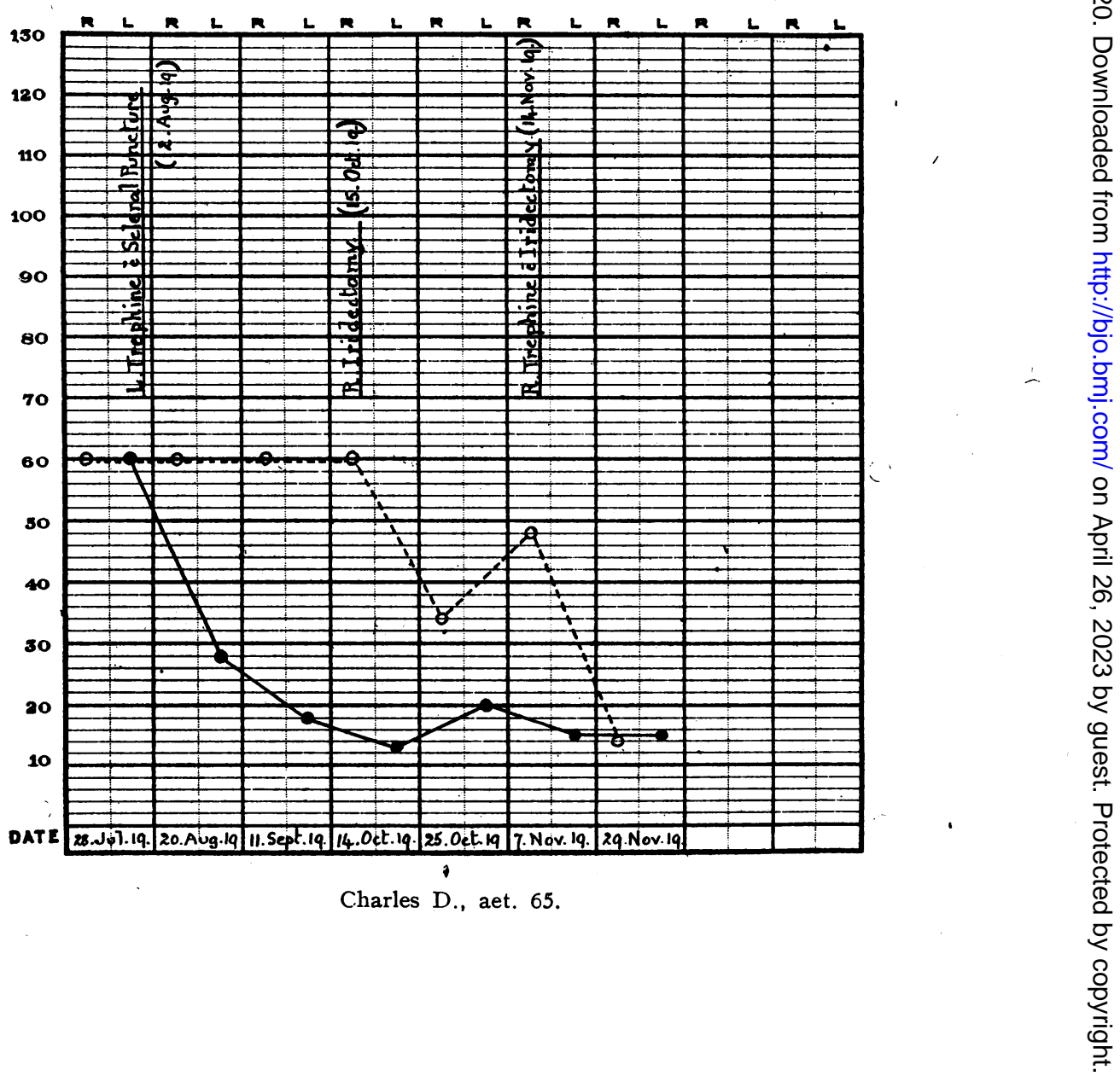

